Article

\title{
A Sightseeing Spot Recommendation System That Takes into Account the Visiting Frequency of Users
}

\author{
Yudai Kato and Kayoko Yamamoto * \\ Graduate School of Informatics and Engineering, University of Electro-Communications, Tokyo 182-8585, Japan; \\ k2030031@edu.cc.uec.ac.jp \\ * Correspondence: kayoko.yamamoto@uec.ac.jp; Tel.: +81-42-443-5728
}

Received: 18 May 2020; Accepted: 26 June 2020; Published: 27 June 2020

\begin{abstract}
The present study aimed to design, develop, operate and evaluate a sightseeing spot recommendation system that can efficiently and usefully support tourists while considering their visiting frequencies. This system was developed by integrating social networking services (SNSs), Web-geographic information systems (GIS) and recommendation systems. The system recommends sightseeing spots to users with different visiting frequencies, adopting two recommendation methods (knowledge-based recommendation and collaborative recommendation methods). Additionally, the system was operated for six weeks in Kamakura City, Kanagawa Prefecture, Japan, and the total number of users was 61. Based on the results of the web questionnaire survey, the usefulness of the system when sightseeing was high, and the recommendation function of sightseeing spots, which is an original function, received mainly good ratings. From the results of the access analysis of users' log data, the total number of sessions in this system was $329,77 \%$ used mobile devices, and smartphones were used most frequently. Therefore, it is evident that the system was used by different types of devices just as it was designed for, and that the system was used according to the purpose of the present study, which is to support the sightseeing activities of users.
\end{abstract}

Keywords: sightseeing spot recommendation system; social networking service (SNS); web-geographic information systems (GIS); recommendation system; visiting frequency; sightseeing spot information

\section{Introduction}

Due to the advancement of information in recent years, anyone can easily send and receive information regardless of time and place, and obtain an abundance of various information from the internet. The same can be said with sightseeing information. Tourists must select necessary information among a significant amount of sightseeing information, and it is tremendously difficult to find information tailored to their purposes. Therefore, it is important to provide tourists with relevant sightseeing information using the internet.

At popular sightseeing sites, there are not only tourists who are visiting for the first time or who have only made a few visits, but there are also repeat travelers who have made several visits. Okamura et al. (2007) [1] identified the difference in sightseeing spots where tourists with different visiting frequencies visited. In this regard, taking up Kamakura City, Kanagawa Prefecture, Japan as an example, the enhancement of sightseeing support for repeat travelers was addressed as one of the issues on sightseeing (Kamakura City, 2016) [2]. Therefore, it is best to provide sightseeing spot information according to the visiting frequency of tourists. This is because it is difficult to use the same method to provide adequate and appropriate support for both tourists that visit for the first time and have limited knowledge and sense of locality, as well as tourists including repeat travelers who have knowledge and sense of locality concerning sightseeing spots. 
Against the above backdrop, the present study aims to develop a sightseeing spot recommendation system that can efficiently and usefully support tourists, taking their visiting frequencies into account. Regarding the system developed in the present study, efficiency is related to the provision of relevant sightseeing information to tourists using the internet, and usefulness is related to the recommendation of sightseeing spots according to tourist preferences and visiting frequencies. This system is designed and developed by integrating social networking service (SNS), Web-geographic information systems (GIS) and recommendation system (Sections 3 and 4). SNS is used to gather, accumulate, evaluate and share sightseeing information. Web-GIS is used to visualize the sightseeing information on digital maps. The recommendation system is used to recommend sightseeing spots to users by taking the difference in the visiting frequencies into account. Additionally, the system will be used by various people from both inside and outside the operation target area during the operation period (Section 5), and improvement strategies will be submitted after the issues are identified by evaluating the system through a web questionnaire survey to users and an access analysis (Section 6).

Kamakura City, Kanagawa Prefecture was selected as the operation target area. The first reason for this selection is that there are many visits by tourists with different visiting frequencies. As mentioned above, Kamakura City is a well-known sightseeing area and the number of visits by repeat travelers has increased in proportion to the enhancements made to the sightseeing support for them. It has also received many first-timer tourists, making it a concentrated location by tourists with different visiting frequencies. The second reason is that Kamakura City has many sightseeing spots such as retail shops and restaurants for tourists in addition to historical buildings. Therefore, it is anticipated that the system can be used to recommend sightseeing spots according to tourist preferences and visiting frequencies.

\section{Related Work}

This system in the present study was developed by integrating multiple systems such as SNS, Web-GIS as well as the recommendation system into a single system. Therefore, the present study is related to three research fields including (1) studies related to sightseeing support systems, (2) studies related to sightseeing information system especially for repeat travelers, and (3) studies related to sightseeing recommendation systems.

Taking up the main preceding studies in recent years, regarding (1) studies related to sightseeing support systems, Anacleto et al. (2014) [3] presented PSiS Mobile, which is a mobile recommendation and planning application designed to support a tourist during his/her vacations. Brilhante et al. (2015) [4] proposed TripBuilder which is an unsupervised framework for planning personalized sightseeing tours in cities, using categorized points of interests (PoIs) from Wikipedia and albums of geo-referenced photos from Flickr. Zhou et al. (2016) [5] and Fujita et al. (2016) [6] developed navigation systems integrating SNS, Web-GIS and augmented reality (AR) to support sightseeing activities during normal times and evacuations during disasters. Based on these studies, Makino et al. (2019) [7] developed a system that visualizes spatiotemporal information in both real and virtual spaces to support sightseeing, integrating SNS, Web-GIS, Mixed Reality (MR) and gallery system as well as Wikitude, and connecting external social media. On the other hand, focusing on the language barrier while sightseeing, Yamamoto et al. (2018) [8] and Abe et al. (2019) [9] proposed sightseeing support systems using English and other nonlinguistic information including pictograms (symbols and marks). Referring to the above studies, Sasaki et al. (2019) [10] developed a sightseeing support system using AR and Pictograms.

For (2) studies related to sightseeing information systems, especially for repeat travelers, McKerche et al. (2014) [11] used global positioning systems (GPS) technology to compare and contrast the behavior patterns of first-time and repeat visitors. Masuda et al. (2012) [12] proposed a system to promote the creation of repeat travelers by providing only nearby information up to the sightseeing spots, and also provide a feeling of incompleteness when they are unable to find what they are looking for. Yorozu et al. (2015) [13] proposed a sightseeing planning support system which recommended 
hidden spots, especially for repeat travelers. Uchizono et al. (2016) [14] proposed a sightseeing recommendation system to increase repeat travelers, focusing on their experiences and interests, and the best season of sightseeing spots. Katayama et al. (2017) [15] developed an information providing system to promote the creation of repeat travelers by providing users with the information concerning hidden spots that are scarcely known but have been visited by others in the past, and have a relatively high satisfaction rate among tourists. Niibara et al. (2017) [16] proposed a system which provides sightseeing information especially for repeat travelers in response to their visit frequencies. Kang et al. (2018) [17] identified the spatial structure of the tourist attraction system by tourists' length of stay, employing anchor-point theory and social network analysis techniques with spatial statistics and using GIS. Uchida et al. (2019) [18] proposed KadaSola, which is a sightseeing support system for long stays to increase repeat travelers, classifying tourists by their attributes.

Regarding (3) studies related to sightseeing recommendation systems, Tarui (2011) [19] combined the collaborative filtering and content analysis methods to develop a system that recommends sightseeing spots from the travel history of users. Yu et al. (2012) [20] proposed a context-aware recommender system that provides personalized mobile travel planning services. Ikeda et al. (2014) [21] developed a social recommendation GIS that recommends sightseeing spots by means of the degree of similarity of sightseeing spots with individual preference information. Based on Ikeda et al. (2014) [21], Mizutani et al. (2017) [22] and Mukasa et al. [23] developed sightseeing spot recommendation systems that respectively take users' circumstances and priority conditions into account. Additionally, Kitayama et al. (2014) [24] developed a route recommender system that takes a user's visit duration at sightseeing locations into account. Gavalas et al. (2014) [25] proposed a mobile tourism recommendation system with context-awareness function. Li et al. (2017) [26] and Takahashi et al. (2017) [27] proposed a tourism course recommendation system using the data obtained from SNS. Aoki et al. (2019) [28] developed a recommendation system that interactively utilizes crowd information to support tour planning.

Regarding (1) studies related to sightseeing support systems, support is provided for sightseeing activities during normal times by means of the functions of submitting, viewing, recommendation, sightseeing planning assistance and navigation. Additionally, support is also provided for evacuation during emergencies by displaying support facilities (evacuation centers, water stations, etc.) on the digital map. Though the systems developed or proposed in (2) studies related to sightseeing information systems especially for repeat travelers promote the increase of repeat travelers, most of these do not provide sightseeing support for them. Regarding (3) studies related to sightseeing recommendation systems excluding Tarui (2011) [19], while sightseeing support through sightseeing spot recommendation by knowledge-based recommendation is conducted, the recommendation of appropriate sightseeing spots according to the preferences of users with different visiting frequencies has not been satisfactory. Additionally, with Tarui (2011) [19], though sightseeing information that suits the preferences of users based on their visiting history can be recommended adopting the collaborative filtering and content analysis methods, users are restricted as they must have experience visiting several sightseeing spots, and the travel history for specific sightseeing spots is not taken into consideration.

In comparison with the preceding studies mentioned above, the first original feature of the present study is that the system can be utilized by users with different travel frequencies including tourists that visit for the first time and have little knowledge and sense of locality as well as tourists who are repeat travelers and have an abundance of knowledge and sense of locality concerning sightseeing spots. The preceding studies did not develop the recommendation systems considering visiting frequency of users. The second original feature is that the system adopts both knowledge-based recommendation and collaborative recommendation as methods to recommend sightseeing spots according to the different preferences of users that occur due to the difference in visiting frequency. Thus, unlike the preceding studies, the system enables the recommendation of favorite sightseeing spots to each tourist according to his/her preferences and visiting frequency. 


\section{System Design}

\subsection{System Characteristics}

As shown in Figure 1, this system is developed by integrating SNS, Web-GIS and the recommendation system. The purpose of this system is to support the sightseeing activities of users with different visiting frequencies, and by adopting both knowledge-based recommendations and collaborative recommendations as recommendation methods, provide appropriate sightseeing spot information that suits the preferences of such users. For users with low visiting frequency such as tourists visiting for the first time, recommendations will be made based on the required conditions entered for sightseeing spots adopting knowledge-based recommendation method. For users with high visiting frequency such as repeat travelers, recommendations will be made based on their information including evaluation history of sightseeing spots, sightseeing spot added to favorites and visiting history adopting collaborative recommendation method. Additionally, combining SNS and Web-GIS, the system enables users to display the evaluation data on digital maps, submit the comments and images for any location as well as create new sightseeing spot information, and easily gather and accumulate sightseeing spot information. As user information is simultaneously saved in the system, the longer the system is operated, the more support that caters to the preferences of users can be provided. In this way, the system can provide efficient support for sightseeing activities by recommending sightseeing spots that take the visiting frequency of users into account.

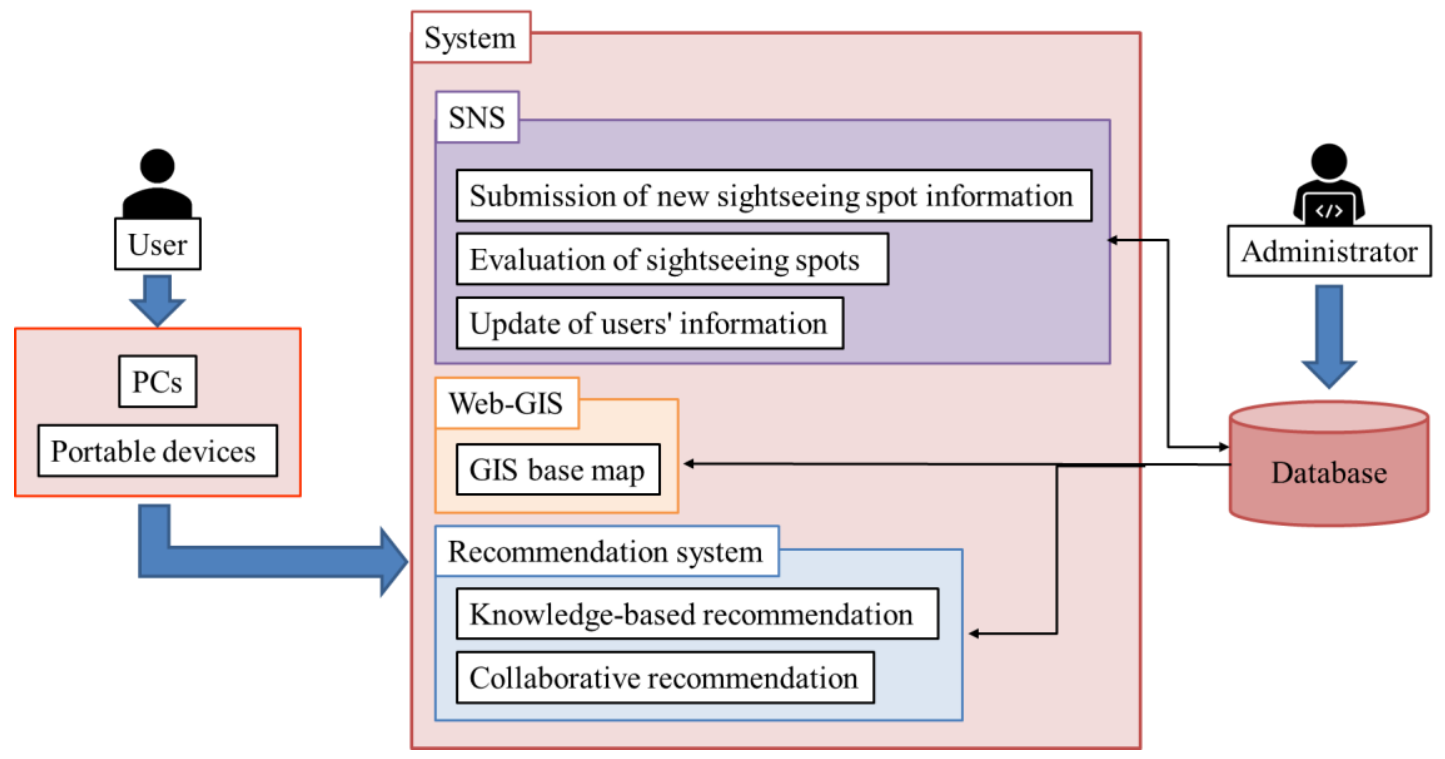

Figure 1. System design.

\subsection{Target Devices}

Though this system is expected to be accessed using PCs and portable devices, same functions can be used from any device as there is no difference in functions depending on the device used. The use from PCs, which are mainly indoors, is assumed to be the sightseeing planning assistance, by gathering sightseeing information, submitting new sightseeing spot information, and evaluating sightseeing spots already accumulated in the system. On the other hand, the main use from portable devices both indoors and outdoors is assumed to be the assistance of sightseeing activities by means of gathering sightseeing information, submitting new sightseeing spot information, and evaluating sightseeing spots already accumulated in the system. 


\subsection{System Operating Environment}

This system is operated using the Web server, database server and the GIS server. The system operating environment is as shown in Figure 2. Heroku, which is a PaaS provided by the Salesforce company, was used for both the Web server and the database server. ArcGIS Online, which is provided by the ESRI, was used for the GIS server. Additionally, the web application developed with the system was implemented using PHP and JavaScript.

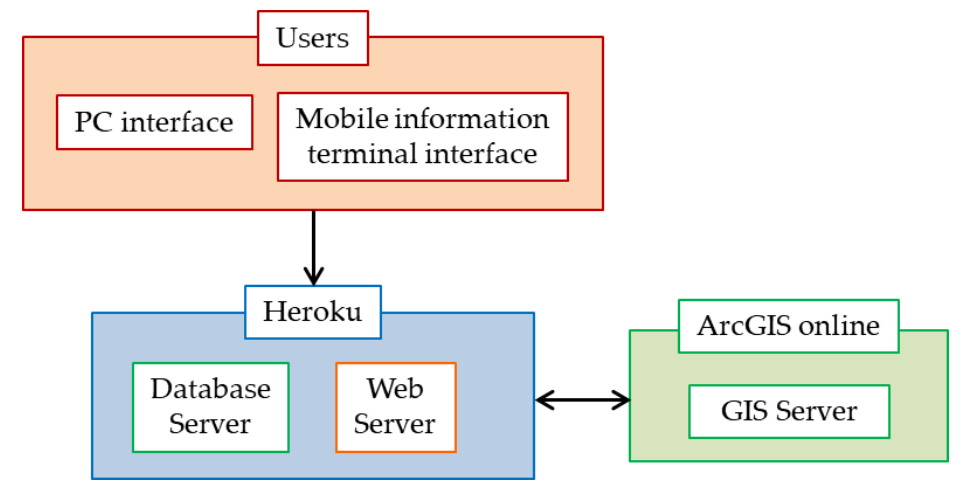

Figure 2. System operating environment.

\subsection{Design of Each System}

\subsubsection{SNS}

The main functions of SNS originally designed in this system are the submitting and viewing of sightseeing spot information. Additionally, using the designed SNS, submitted information, "favorite sightseeing spots" and "visited sightseeing spots" can be made public.

\subsubsection{Web-GIS}

Though there are many types of Web-GIS, this system uses ArcGIS API for JavaScript provided by the ESRI to display the location of recommended sightseeing spots, as it is convenient to access the websites without the installation of any software. Additionally, Leaflet, which is the JavaScript open-source map library using JavaScript, is used to display the recommendation results for sightseeing spots as well as the location of submitted information and sightseeing spots in the page for the detailed information of sightseeing spot.

\subsubsection{Recommendation System}

1. Selection of the recommendation methods

According to Jannach et al. (2011) [29] and Kamishima (2008) [30], there are three types of recommendation methods, including collaborative recommendation, content-based recommendation, and knowledge-based recommendation, that can make recommendations from vast information groups to match the preferences of users. This system is expected to be used by two types of users: users who visit a sightseeing spot for the first time, and users who have visited several times (repeat travelers). Therefore, the system will adopt the knowledge-based recommendation and collaborative recommendation methods. The knowledge-based recommendation method was selected, as it is the best method for users that visit a sightseeing spot for the first time and have little knowledge and sense of locality. The method can recommend appropriate sightseeing spots, by explicitly asking for preferences and creating preference data of users who receive recommendations. On the other hand, the collaborative recommendation method was selected, as it is the best method for users such as repeat travelers who have their own preferences based on their previous visits to the sightseeing spots. 
The method can recommend appropriate sightseeing spots which suit the preferences of users, by referring to the utilization and preference information of users.

Additionally, the cold-start problem can be solved by adopting the knowledge-based recommendation method. Cold start is a problem where appropriate recommendations cannot be made due to insufficient past information. Since knowledge-based recommendations are conducted by creating preference data of users, appropriate recommendations can be made without any past information by explicitly asking for their preferences beforehand.

\section{Knowledge-based recommendation system}

Regarding the knowledge-based recommendation method, user profiles are created by having users evaluate the items set beforehand on a scale of 1 to 5 . The created user profile is set as the user's characteristic vector. Regarding the evaluation data of sightseeing spots also, characteristic vectors for sightseeing spots are created by evaluating each item on a scale of 1 to 5 . Based on the created characteristic vectors of users and sightseeing spots, a maximum of 10 sightseeing spots in descending order of similarity will be recommended by calculating the degree of similarity using Equation (1).

$$
\operatorname{Sim}_{i}=\frac{\sum_{j=1}^{n} U_{j} \times S_{i j}}{\sqrt{\sum_{j=1}^{n}\left(U_{j}\right)^{2}} \times \sqrt{\sum_{j=1}^{n}\left(S_{i j}\right)^{2}}}
$$

$\operatorname{Sim}_{i}$ : Degree of Similarity

$U_{j}$ : Preference information of user $i$

$S_{i j}$ : Evaluation data of sightseeing spots

3. Collaborative recommendation system

According to Kamishima (2007) [30], collaborative filtering (collaborative recommendation in the present study) method can be divided into memory-based method and model-based method. The memory-based method of collaborative recommendation system was selected, as user information will be accumulated in the database, and the preference information of users will be expected to be insufficient right after the start of the operation of this system.

Additionally, according to Kamishima (2007) [30], the memory-based method can be divided into two types: user-based type and item-based type. The system will adopt item-based type of collaborative recommendation system for the same reason memory-based method was selected which is that the lack of preference data of users can be expected right after the start of the operation of the system. This method enables recommendations to be made based only on the preference data of users, by accumulating the evaluation data of sightseeing spots beforehand. Regarding the preference data of users, they can be gathered by registering the evaluation data of sightseeing spots as well as "favorite sightseeing spots" and "visited sightseeing spots" using the designed SNS in Section 3.4.1. Therefore, the system will use the item-based type to develop a memory-based collaborative recommendation system. More specifically, the Item-Based Neighborhood Model proposed by Aggrawal (2016) [31] will be used. First, the degree of similarity between sightseeing spots is calculated using Equation (2) from the evaluation data of sightseeing spots accumulated in the database of the system.

$$
\operatorname{Sim}(i, j)=\frac{\sum_{u \in U_{i} \cap U_{j}}\left\{\left(r_{u i}-\underline{r_{u}}\right) \times\left(r_{u j}-\underline{r_{u}}\right)\right\}}{\sqrt{\sum_{u \in U_{i} \cap U_{j}}\left(r_{u i}-\underline{r_{u}}\right)^{2}} \times \sqrt{\sum_{u \in U_{i} \cap U_{j}}\left(r_{u j}-\underline{r_{u}}\right)^{2}}}
$$

$\operatorname{Sim}(i, j)$ : Degree of Similarity between sightseeing spot $i$ and sightseeing spot $j$

$r_{u i}$ : Evaluation data of sightseeing spot $i$ by user $u$ 
$\underline{r_{u}}:$ Average value of evaluation data of user $u$

At the same time, user profiles will be created based on the users' evaluation data of sightseeing spots registered in the system using the designed SNS in Section 3.4.1. Aside from the users' evaluation data, the evaluation values of sightseeing spots according to each category as calculated using Equation (3) are added to the evaluation values of sightseeing spots that belong to their respective categories, based on the data of "favorite sightseeing spots" and "visited sightseeing spots" registered by users.

$$
C_{i}=5 \times \frac{s_{u i}}{I_{u}}
$$

$C_{i}$ : Evaluation data of category $i$

$I_{u}$ : Number of favorites and visits of user $u$

$s_{u i}$ : Number of favorite sightseeing spots and visited sightseeing spots of user $u$

Next, for sightseeing spots that are not evaluated by users, the estimated evaluation values of users are calculated using Equation (4), based on the degree of similarity between sightseeing spots and user profiles, and up to 10 sightseeing spots will be recommended in the descending order of the estimated evaluation value.

$$
p_{u t}=\frac{\sum_{j \in Q_{t(u)}} \operatorname{Sim}(j, t) \times p_{u j}}{\sum_{j \in Q_{t(u)}}|\operatorname{Sim}(j, t)|}
$$

$p_{u t}$ : Estimated evaluation values of sightseeing spots that have not been evaluated by users $Q_{t(u)}$ : Aggregation of sightseeing spots evaluated by user $u$

\section{System Development}

\subsection{The Front-End of the System}

This system will implement unique functions for users, which will be mentioned below, in response to the purpose of the present study, as mention in Section 1. In order to implement these several unique functions, the system was developed by integrating plural systems into a single system. Additionally, the system was operated targeting Japanese people and those who can understand Japanese, while selecting Kamakura City, Japan as the operation target area. Therefore, all websites included in the system are written in Japanese with English notations.

1. Viewing function of sightseeing spots

Users are transferred to the page for the viewing function of sightseeing spot information (Figure 3) from the "Kamakura area map" in the menu of the top page. This page allows users to search for sightseeing spots using "search from map" or "search by category". When using "search from map", a popup including the "name of sightseeing spot", "category" and "link to the page for the detailed information of sightseeing spot (Figure 4)" will be displayed, by clicking onto the markers on the digital map. Additionally, the markers are color-coded according to category. On the other hand, when using "search by category", sightseeing spots will be displayed in a list according to category. Users are transferred to the page for the detailed information of sightseeing spots by selecting a sightseeing spot from the list. Additionally, users who have created their own account and log in to the system can register their "favorite sightseeing spots" and "visited sightseeing spots", by clicking onto the buttons of "register favorites" and "register past visits" from the list.

In the page for the detailed information of sightseeing spot (Figure 4), the "name of sightseeing spot", "category", "postal code", "address", "link (external site of the sightseeing spot)", "details (sightseeing spot information)" and "number of comments on the sightseeing spot" as well as the "image of the sightseeing spot" and "map" are displayed. The buttons of "register favorites" and "register page 
visits" are displayed on this page, and users can use them to register their "favorite sightseeing spots" and "visited sightseeing spots". The link for each category transfers users to the list of sightseeing spots for the selected category, while the link in the comments on a sightseeing spot transfers users to the list of comments. Additionally, the link of "click here to update sightseeing spot information" transfers users to the page for the editing of sightseeing spot information. This page allows users to update information, excluding the "name of sightseeing spot", "category", "image" and "location information".

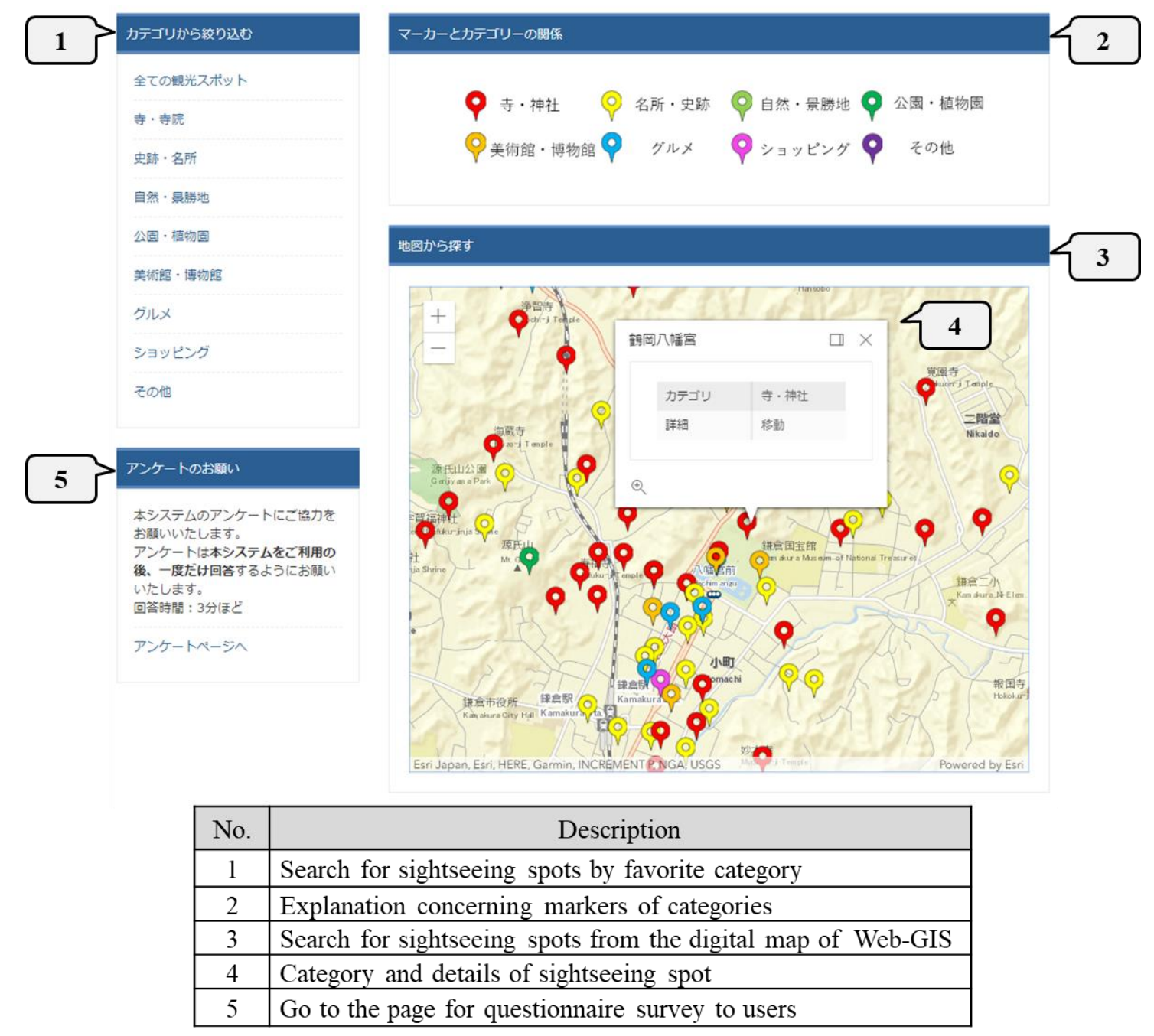

Figure 3. Page for viewing function of sightseeing spots. 


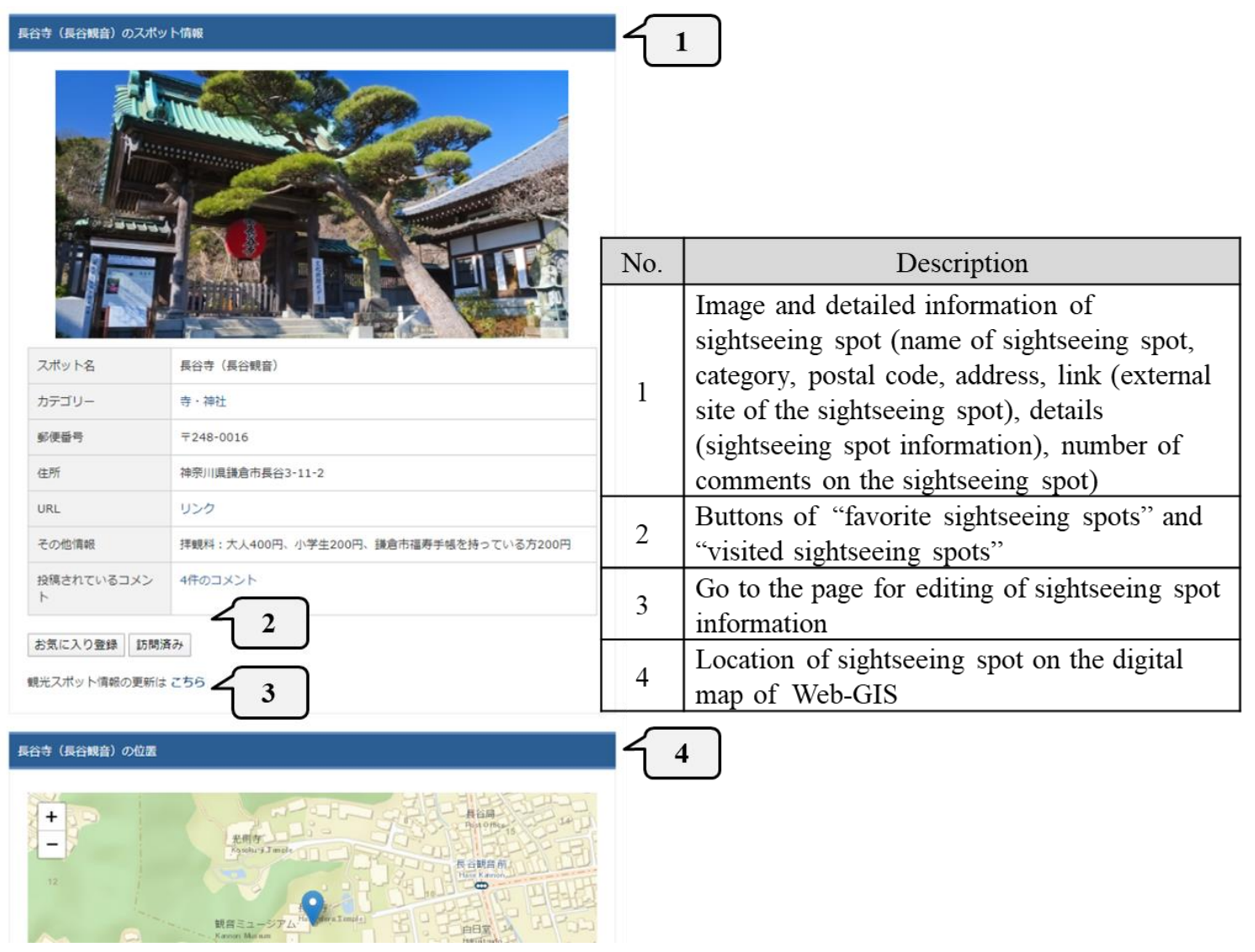

Figure 4. Page for detailed information of sightseeing spot.

2. Submitting function of sightseeing spots

Users are transferred to the page for the submitting function of sightseeing spots (Figure 5) from the "submitting function" in the menu of the top page. In this page, information on a location can be submitted by entering the "name of sightseeing spot", "title", "category", "comment", "image" and "evaluation for each item", and clicking onto the location on the digital map or by acquiring the present location information. For each evaluation item, five items including the "satisfaction level", "access", "non-crowdedness", "landscape", and "accessibility for those with special need" must be evaluated on a scale of 1 to 5 . Regarding the scale, " 5 " means the best and " 1 " means the worst. Additionally, in the page for this function, users can be transferred to the list and map of submitted information. Users can visit the page for the submitted information list from the page for the submitting function of sightseeing spots as well as the top page. This page displays the "title", "name of sightseeing

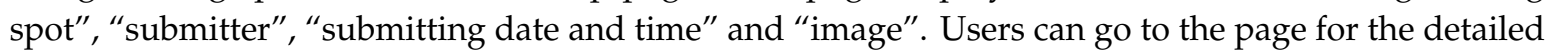
information of sightseeing spot, by selecting one of the submitted information.

Regarding the map with submitted information, markers are displayed on the digital map based on the location information from the submitted information. By clicking onto a marker, a popup including the "title", "name of sightseeing spot", "category", "submitter", "submitting date and time" and "comments" is displayed. These markers are color-coded according to category. On the page for the detailed information of sightseeing spots, the "title", "target sightseeing spots", "category", "submitter" and "comments" as well as "submitted image" and "map" are displayed. Selecting a target sightseeing spot leads to the page for the detailed information of sightseeing spots, selecting a category leads to the page for the submitted information list of such category, and selecting a submitter leads to the My Page of the person who submitted the information. Additionally, only the administrator 
and the user who submitted the information can go to the page for the editing of sightseeing spot information to delete submitted information.

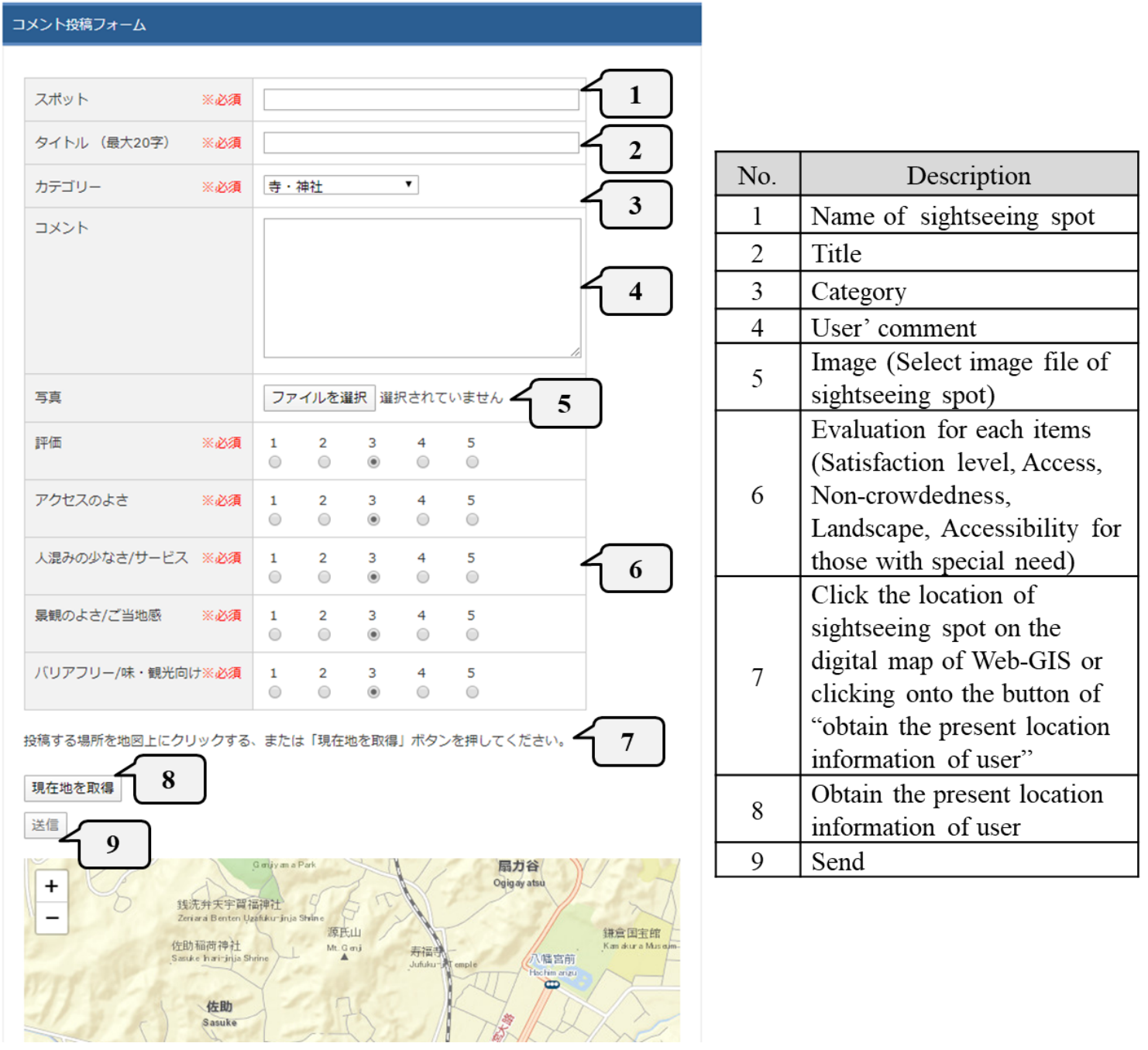

Figure 5. Page for submitting function of sightseeing spots.

3. Recommendation function of sightseeing spots

Users are transferred to the page for the recommendation function of the sightseeing spots adopting knowledge-based recommendations (Figure 6) from the "recommendation conditions" in the menu of the top page. By clicking onto the button of "send" after evaluating each items for sightseeing spots on a scale of 1 to 5 , and selecting the range of recommendation results from "main station" and "distance $(250 \mathrm{~m}, 500 \mathrm{~m}, 1 \mathrm{~km}$, or not specified) from the mains station", users can go to the page for the recommendation results. The center of recommendations can be set as users' present locations by using their present location information. Additionally, users can be transferred to the recommendation function of sightseeing spots adopting collaborative recommendations from the "recommended spots" in the menu of the top page. Sightseeing spots are recommended in the same way as the recommendation function of the sightseeing spots adopting knowledge-based recommendations. 


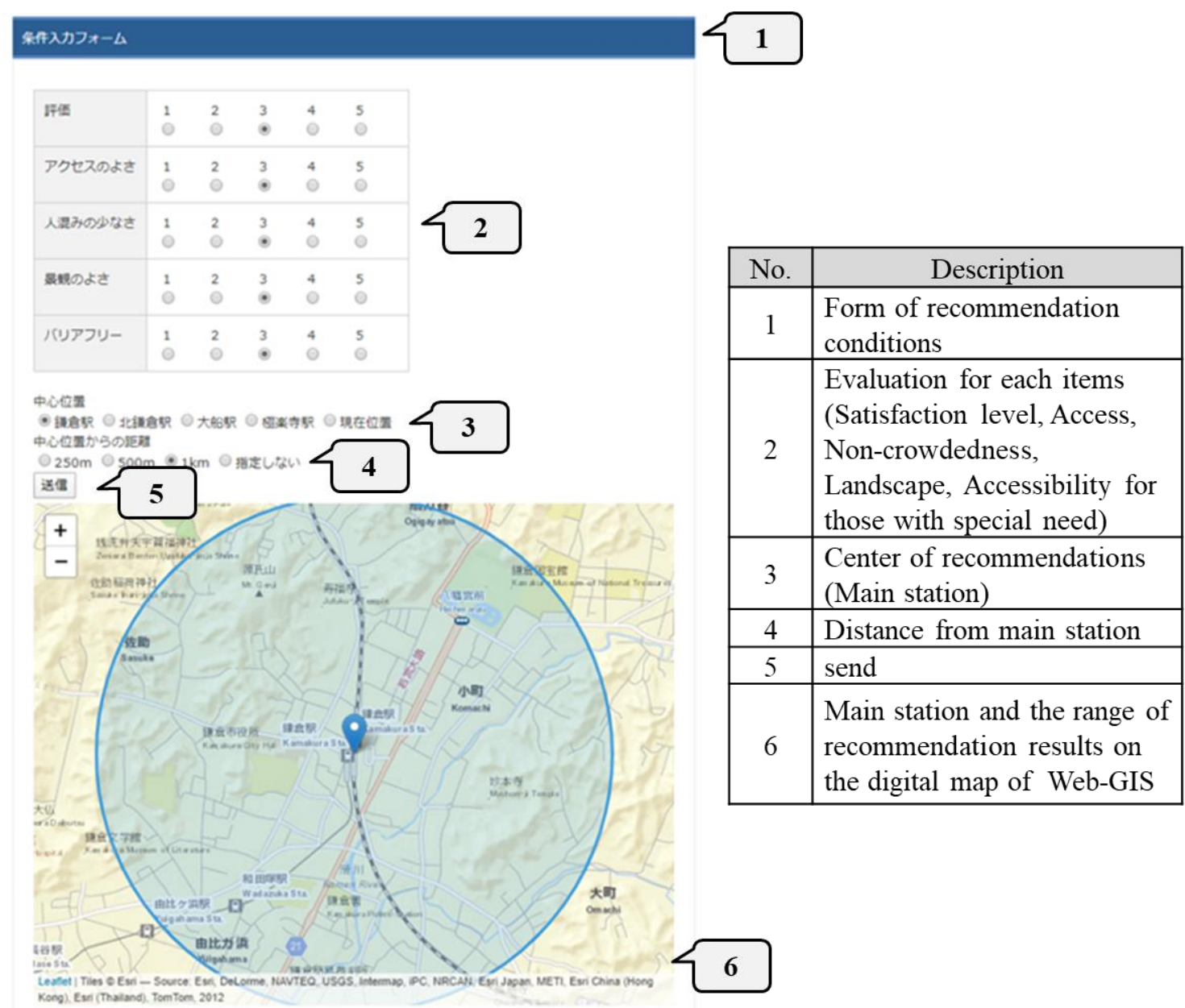

Figure 6. Page for recommendation function of sightseeing pots adopting knowledge-based recommendations.

Users can go to the page for the recommendation results (Figure 7) by clicking onto the button of "send" on the pages of "recommendation conditions" and "recommended spots". The page for the recommendation results displays a list of sightseeing spots (up to 10) that were recommended as well as the map with the locations. A popup containing the "name of sightseeing spot", "category", and the "link to the page for the detailed information of sightseeing spot" can be displayed, by clicking onto the markers on the digital map. These markers are color-coded according to category. The list of recommended sightseeing spots and the links in the popups lead to the link to the page for the detailed information of sightseeing spot. 


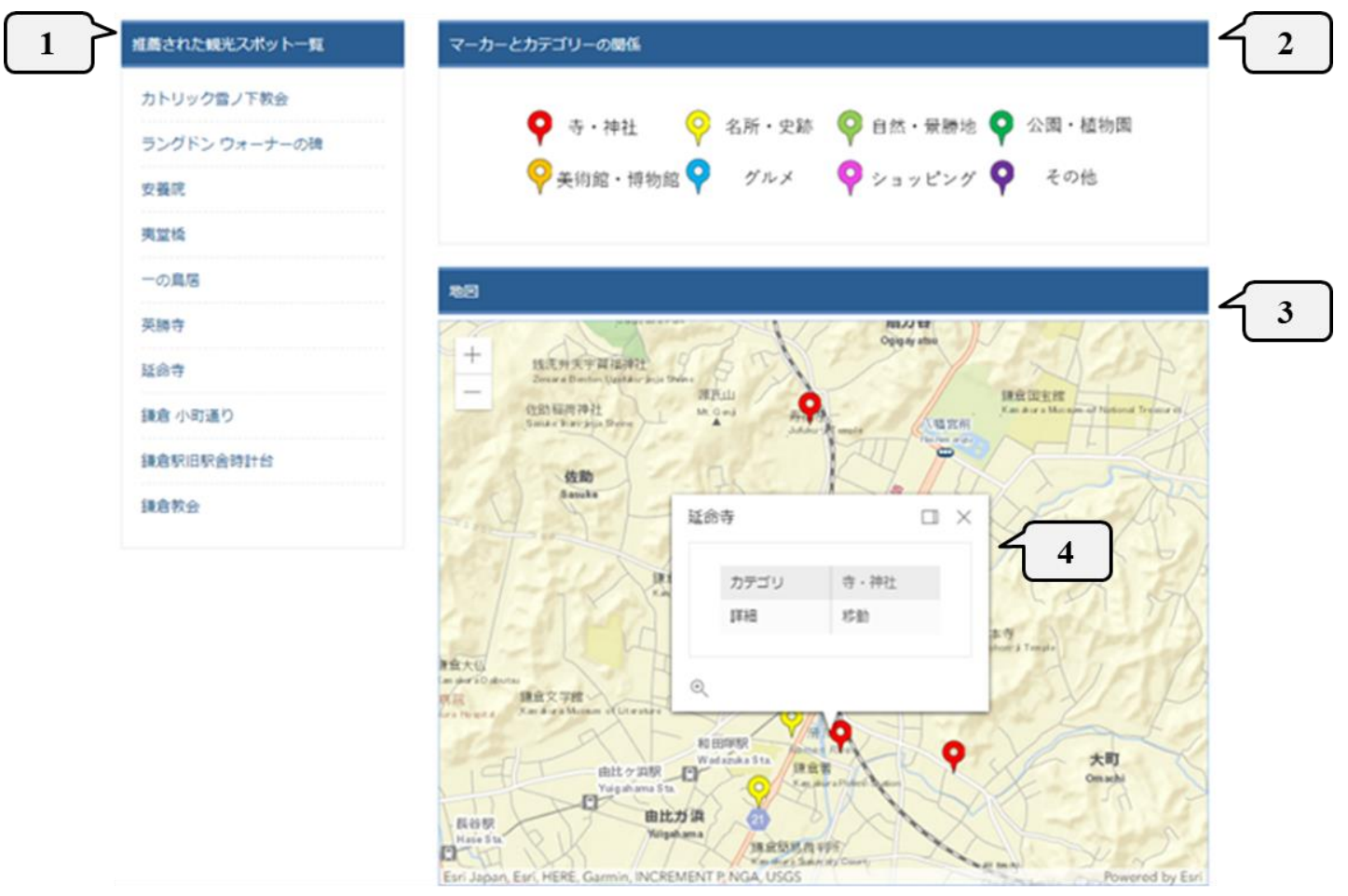

\begin{tabular}{|c|l|}
\hline No. & \multicolumn{1}{|c|}{ Description } \\
\hline 1 & List of recommended sightseeing spots \\
\hline 2 & Explanation concerning markers of categories \\
\hline 3 & Locations of recommended sightseeing spots on the digital map of Web-GIS \\
\hline 4 & Category and details of sightseeing spot \\
\hline
\end{tabular}

Figure 7. Page for recommendation results.

\subsection{The Back-End of the System}

1. Processing concerning the evaluation of sightseeing spots

In order to improve the accuracy of the recommendation function of sightseeing spots, users are asked to evaluate sightseeing spots using the designed SNS in Section 3.4.1. and new evaluation values are calculated with the back-end of this system.

\section{Processing of knowledge-based recommendations}

The back-end of the system is used for the process of calculating the degree of similarity adopted to recommend sightseeing spots to users, creating user profiles based on the preference information entered by users, and narrowing of sightseeing spots within the range of the recommendation results to be displayed. Users can receive recommendations, by entering their preference information and the range of recommendation results for sightseeing spots.

\section{Processing of collaborative recommendations}

The calculation process for the degree of similarity between sightseeing spots, the evaluation information of sightseeing spots obtained through the users' SNS, the degree of similarity between the user profile created from the registered information such as "favorite sightseeing spots" and "visited sightseeing spots" and evaluation data of sightseeing spots were used. The back-end of the system was used for the calculation process of the estimated evaluation values of unevaluated sightseeing spots, and the narrowing process of sightseeing spots within the range of the recommendation results 
entered by users. After the users have used each function of SNS, they can receive recommendations by entering the range of recommendation results for sightseeing spots.

\subsection{System Interface}

The interface of this system has two types: the PC and portable device screen of users, and the PC screen of the administrator. For the users' screen, a responsive design was selected and two types of interfaces were prepared according to the screen size of the devices used. For the administrator's page, users, sightseeing spot information, and submitted information can be managed. By utilizing Graphic User Interface (GUI), malicious users and inappropriate sightseeing spot information can be deleted without being affected by the information technology (IT) literacy of the administrators.

\section{Operation}

\subsection{Sightseeing Spot Data}

\subsubsection{Data Gathering}

The sightseeing spot information must be gathered beforehand in order to enable the use of the functions just after the start of the operation of this system. A total of 133 places of sightseeing spot data were gathered in Kamakura City, Kanagawa Prefecture that were evaluated in the travel review site of 4travel.jp [32] as well as in the Jalan Kankou Guide [33].

\subsubsection{Data Processing}

Though the sightseeing spot data gathered in the previous section were divided into six categories including "temple", "famous and historical site", "art museum and museum", "beach", "nature and scenic site" and "park and botanical garden", information on "restaurant" can be expected to be submitted during the operation of this system. Therefore, the categories were reconsidered based on the travel review site of 4travel.jp [32] as well as in the Jalan Kankou Guide [33]. As a result, eight categories including "temple", "famous and historical site", "nature and scenic site", "park and botanical garden", "art museum and museum", "food", "shopping" and "others" were put in place, and the 133 sightseeing spots were re-categorized. The "others" category includes hot springs, lodgings and events.

\subsection{User Assumption}

This system is expected to be used by various users such as those who are planning on visiting the operation target area for the first time, and those who have already visited the operation target area and are planning another visit. Since those who visit for the first time can be expected to have little knowledge and sense of locality, the knowledge-based recommendation method that does not require previous knowledge will be adopted as a tool to gather sightseeing spot information. For those who have visited the operation target area several times and already have knowledge and sense of locality, the collaborative recommendation method will be adopted as a tool to gather sightseeing spot information that suits their individual preferences based on their visiting history. Additionally, all users who are both indoors and on-site will be encouraged to submit evaluations for sightseeing spots that they have visited and sightseeing spot information that have not been registered.

\subsection{Operation}

\subsubsection{Operation Overview}

The operation of this system was conducted over the course of six weeks with people inside and outside the operation target area as subjects. The authors promoted the use of the system through the website, Twitter and Facebook of their labs. Users will register when using the system for the first 
time. Registration is completed by entering their account names, email addresses, genders, age groups, numbers of past visits to Kamakura City and passwords. The email address and password are required when logging in to the system. Users are automatically transferred to the top page only after the initial registration. After completing the registration process, users can use all the functions of the system only if they are logged in. While the "Kamakura area map" and other information concerning Kamakura area can be utilized without logging in, "favorite sightseeing spots" and "visited sightseeing spots" cannot be registered. The My Page can be used to change the information concerning users and their preferences which will enable them to receive recommendations of sightseeing spot that suit individual preferences.

\subsubsection{Operation Results}

The users of this system are shown in Table 1. There were a total of 61 users including 44 men and 17 women. There were no incentives for users, and those who wanted to use the system had to register when using the system for the first time, as mentioned in the previous section. There were more male users and males in their 20s made up the highest percentage. Regarding age groups, users in their 20s made up the highest percentage of $64 \%$ including both men and women. Users in their $50 \mathrm{~s}$ made up $13 \%$, users aged 60 and over made up 10\%, users in their 10 s made up $5 \%$, users in their 30 s made up $7 \%$, and the lowest percentage was users in their 40 s who only made up $2 \%$. All users are Japanese, and their places of residence mainly concentrate in the Kanto region (the Tokyo metropolitan area). Additionally, as a result of the operation, more than half of the users were young people who are familiar with new technologies.

Table 1. Breakdown of system users and web questionnaire survey respondents.

\begin{tabular}{cccccccc}
\hline Age Groups of Users & $\mathbf{1 0 - 1 9}$ & $\mathbf{2 0 - 2 9}$ & $\mathbf{3 0 - 3 9}$ & $\mathbf{4 0 - 4 9}$ & $\mathbf{5 0 - 5 9}$ & $\mathbf{6 0 -}$ & Total \\
\hline Number of Users & 3 & 39 & 4 & 1 & 8 & 6 & 61 \\
Number of Web Questionnaire & 1 & 36 & 4 & 1 & 6 & 5 & 53 \\
Survey Respondents & 33.3 & 92.3 & 100 & 100 & 75.0 & 83.3 & 86.9 \\
Valid Response Rate (\%) & &
\end{tabular}

Regarding the number of visits to the operation target area before using the system, based on the classification of tourists focusing on visiting frequency in Adachi et al. (2007) [34], those with zero visits are defined as "first-time visitors", 1-2 visits are "few-time visitors", 3-5 visits are "semi-repeat travelers", and 6-11 or more visits are "repeat travelers". According to this definition, $16 \%$ of users were first-time visitors, $25 \%$ were few-time visitors, $14 \%$ were semi-repeat travelers, and $45 \%$ were repeat travelers. In this way, the percentage of repeat travelers was high for both men and women, and there were also many first-time and few-time visitors. Therefore, it is evident that the system was used by people with different visiting frequencies including first-time and few-time visitors who have limited knowledge and sense of locality as well as semi-repeat travelers and repeat travelers who have sufficient knowledge and sense of locality concerning sightseeing spots.

Additionally, the number of new sightseeing spots submitted during the operation was 22, and the number of evaluations for sightseeing spots that were accumulated in the system before the operation was 45 . Therefore, it can be expected that the number of submissions for new sightseeing spot information as well as the evaluations for accumulated sightseeing spots will increase, by conducting the operation of the system on a long-term basis.

\section{Evaluation}

In this section, first of all, the system developed in the present study will be evaluated based on the results of a web questionnaire survey to users and an access analysis of users' log data. Next, based on the results, improvement strategies for the system will be submitted. 


\subsection{Evaluation Based on the Web Questionnaire Survey}

\subsubsection{Overview of the Web Questionnaire Survey}

According to the purpose of the present study, a web questionnaire survey was carried out in order to conduct an (1) evaluation concerning the system utilization as well as an (2) evaluation concerning the overall system and original functions. This questionnaire survey was carried out on the website one week after the operation commenced. The overview of the questionnaire survey is also shown in Table 1. As shown in Table 1, 53 people out of the 61 users responded which is an $87 \%$ valid response rate. The second evaluation focused on the original functions of this system used by users on their own initiative.

\subsubsection{Evaluations Concerning the System Utilization}

1. Evaluation concerning the compatibility with the information acquisition methods of sightseeing spots

Regarding the information acquisition methods for sightseeing spots (multiple answers allowed), $31 \%$ answered PCs, 57\% answered portable devices, and 11\% answered guidebooks. This result clearly shows that the methods used to acquire sightseeing information mostly involve the use of the internet from PCs or portable devices such as smartphones and not only printed media such as guidebooks. Therefore, it is evident that this system was effective in supporting sightseeing activities, as it enabled users to acquire sightseeing spot information using their PCs or portable devices.

2. Evaluation concerning the status of system utilization

Regarding the devices used to access the system, 21\% answered PC while 79\% answered smartphones, showing that the system is mostly accessed from smartphones. For the purpose of using the system (multiple answers allowed), 37\% answered "Gather sightseeing information", 34\% answered "Create travel plans", and 27\% answered "On-site travel". Therefore, this results show that each purpose has the same level of demand. Based on the above, situations in which the system can be utilized were expanded by preparing an interface for portable devices in addition to one for PCs.

\subsubsection{Evaluations Concerning the Overall System and Original Functions}

1. Evaluations concerning the overall system and the submitting function of sightseeing spots

Regarding the usefulness of this system while sightseeing, 51\% answered "I think so" and 47\% answered "I somewhat think so", and 2\% answered "I don't think so". Therefore, the system can be considered useful in supporting sightseeing activities. For the submitting function of sightseeing spot information, only $30 \%$ of those who responded to the questionnaire survey used the function. Users that had not used the function gave reasons such as "I didn't have any sightseeing spot information", "I didn't want to submit sightseeing spot information", "It takes time to enter information in the submitting form", and "The design of the page makes it difficult to submit". Therefore, it was revealed that improvements were necessary as the reasons provided that were related to the design of the page for the submitting function of sightseeing spot information.

2. Evaluations concerning the overall recommendation function of sightseeing spots

The evaluation results concerning the overall recommendation function of sightseeing spots, which is an original function in the system, are shown in Figure 8. Regarding the suitability of sightseeing spots recommended (10 spots), 98\% answered "I think so" or "I somewhat think so". Therefore, it was appropriate to recommend several sightseeing spots. For the usefulness to display sightseeing spots recommended on digital map, and the usefulness to specify range of recommendation results for sightseeing spots, 96\% answered "I think so" or "I somewhat think so". From these results, 
it can be considered effective to allow users to select a range when recommending sightseeing spots as well as display them on the digital map of Web-GIS.

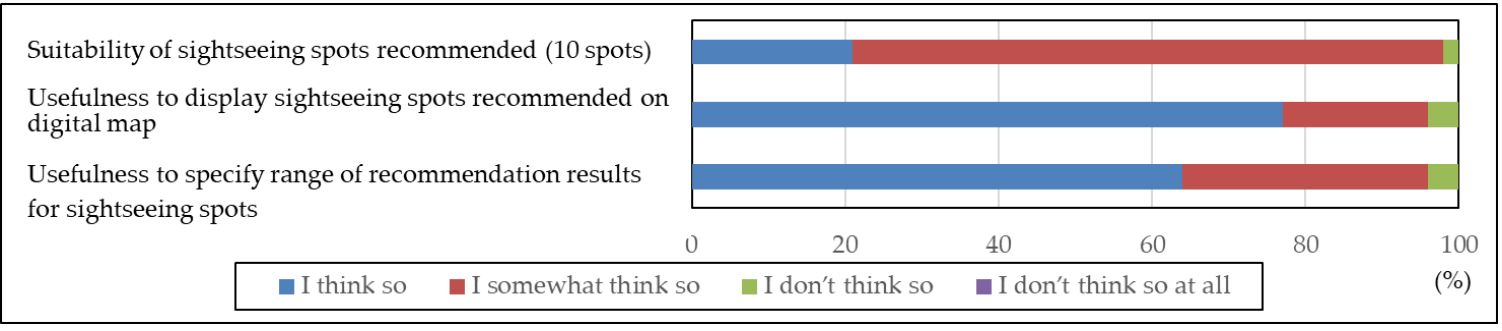

Figure 8. Evaluations concerning the overall recommendation function of sightseeing spots.

3. Evaluations concerning the recommendation function of sightseeing spots adopting knowledge-based recommendations

The evaluation results concerning the recommendation function of sightseeing spots adopting knowledge-based recommendations are shown in Figure 9. As mentioned in Section 6.1, when using this function, users must enter their recommendation conditions for sightseeing spots. The function was used by $72 \%$ of those who responded to the questionnaire survey. Regarding the compatibility of the recommended sightseeing spots with the preferences of users, $92 \%$ of those who used the function answered "I think so" or "I somewhat think so". For the suitability of recommendation conditions for sightseeing spots, $97 \%$ answered "I think so" or "I somewhat think so". Additionally, for the satisfaction rate of the sightseeing spots recommended, $90 \%$ answered "I think so" or "I somewhat think so".

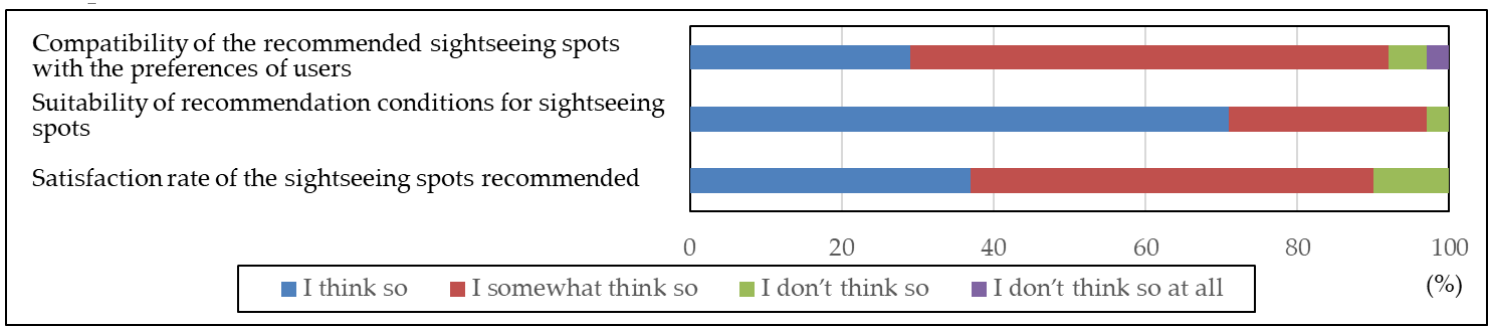

Figure 9. Evaluations concerning the recommendation function of sightseeing spots adopting knowledge-based recommendations.

From these results, sightseeing spots recommended by adopting the knowledge-based recommendation method, which is based on the preference information of users obtained by recommendation conditions selected by users, matched the preferences of users. On the other hand, users who did not use the function answered that "I couldn't find it". This may be because it was hard to find the buttons leading users to the page for the function, when using the system from smartphones.

4. Evaluations concerning the recommendation function of sightseeing spots adopting collaborative recommendations

The evaluation results concerning the recommendation function of sightseeing spots adopting collaborative recommendations are shown in Figure 10. This function was used by $81 \%$ of those who responded to the questionnaire survey. Regarding the compatibility of the recommended sightseeing spots with the preferences of users, $91 \%$ of those who used the function answered "I think so" or "I somewhat think so". For the Satisfaction rate of the sightseeing spots recommended, $95 \%$ answered "II think so" or "I somewhat think so". Therefore, sightseeing spots recommended adopting the collaborative recommendation method, which is based on the preference information and evaluation history of users, and matched the preferences of users. 


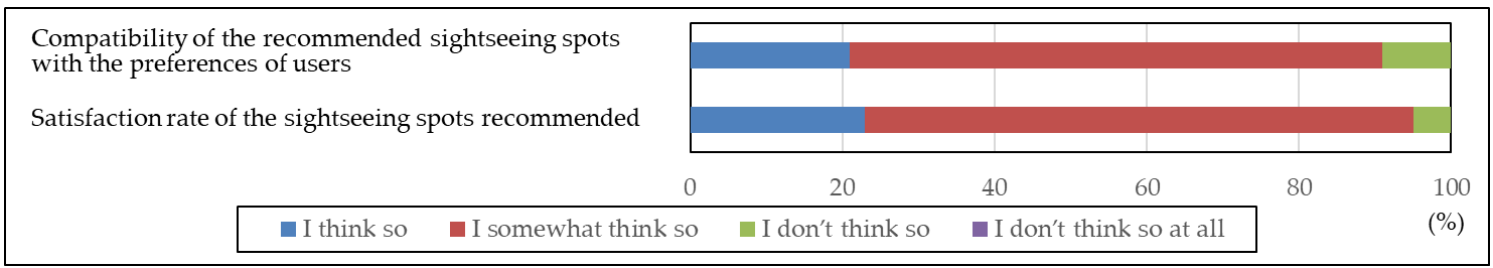

Figure 10. Evaluations concerning the recommendation function of sightseeing spots adopting collaborative recommendations.

\subsection{Evaluations Based on the Access Analysis}

An access analysis was conducted in the present study using the log data of users during the operation period. The present study used the Google Analytics of Google. The access log can be obtained by calling the Python Program, which contains the analysis code created with Google Analytics, from the HTML file read on each page within the website subject to the access analysis.

The total number of sessions in this system was 329. Regarding the devices used to access the system, $23 \%$ used PCs, $74 \%$ used smartphones, and 3\% used PC tablets. The reason for this is that smartphones have been used most frequently as a convenient information acquisition method in recent years. Therefore, it can be considered effective to design the system to be used equally regardless of the type of device in order to eliminate the difference in obtaining information.

The top 10 visited pages are shown in Table 2. As evident from Table 2, the pages for the recommendation conditions and the recommendation function of sightseeing spots are frequently accessed. Therefore, the system was used in line with the purpose of the present study which was to support sightseeing activities of users with different visiting frequencies adopting different methods. Additionally, the pages for the "Kamakura area map" to view sightseeing spot information and submitting function of sightseeing spot information were also frequently accessed. However, as the access number of the page for the submission completion was low, it can be presumed that users visited the page for the submitting function of sightseeing spot information, but did not make any submissions. As mentioned in Section 6.1.3, the reason for this is considered to be related to the users and the design of the website.

Table 2. Number of visits for each page (top 10).

\begin{tabular}{cccc}
\hline Rank & Page Name & $\begin{array}{c}\text { Number of } \\
\text { Visits }\end{array}$ & Percentage (\%) \\
\hline 1 & Top page & 288 & 20.4 \\
2 & Page for “Kamakura area map" & 103 & 7.3 \\
3 & Page for submitting function of sightseeing spot information & 82 & 5.8 \\
4 & Page for creating of an account of user & 70 & 5.0 \\
5 & Page for recommendation conditions & 65 & 4.6 \\
6 & Page for recommendation function of sightseeing spots & 61 & 4.3 \\
7 & Login page & 43 & 3.0 \\
8 & Page for recommendation function of sightseeing spots & 40 & 2.8 \\
9 & adopting knowledge-based recommendations & 38 & 2.7 \\
10 & Page for submitted information list & 31 & 2.2 \\
\hline
\end{tabular}

\subsection{Submission of Improvement Strategies}

The tasks concerning this system submitted based on the results of the questionnaire survey and the access analysis are summarized below. 


\section{Web-page design}

It is essential to create a web-page design that enables users to easily view sightseeing spot information, easily notice the information users are lacking, and easily and quickly make information updates. This will promote the use of other functions related to recommendation and submitting in addition to the information updates.

\section{Recommendation function of sightseeing spots}

It is necessary to implement the recommendation function according to category, and a function that allows for changes to the number of sightseeing spots to be displayed according to the range of recommendation results for sightseeing spots. This will improve the compatibility of the recommended sightseeing spots with the preferences of users as well as the visibility of recommendation results, enabling users to create a more detailed travel plan.

\section{Submitting function of sightseeing spots}

It is necessary to implement the functions such as submitting new sightseeing spot information, evaluating sightseeing spots already accumulated in the system, and submitting comments and images on different pages. Additionally, it is essential to submit from the digital map or the page for the detailed information of sightseeing spot, and visualize other users' reactions using the "like" button. These aspects will promote the use of the submitting function of sightseeing spot information to users. Furthermore, the accuracy of the recommendation results for sightseeing spots will be improved, as this will allow for the gathering and accumulation of more sightseeing spot information.

\section{Conclusions}

In the present study, a system was designed and developed (Sections 3 and 4), the operation was implemented (Section 5), and evaluations and the submission of improvement strategies were conducted (Section 6). In comparison with the systems in sightseeing spot services for tourists developed in the preceding studies mentioned in Section 2, the system developed in the present study can be utilized by users with different travel frequencies including tourists that visit for the first time and have little knowledge and sense of locality, as well as tourists who are repeat travelers and have an abundance of knowledge and sense of locality concerning sightseeing spots. Additionally, the system adopted both knowledge-based recommendation and collaborative recommendation as methods to recommend sightseeing spots according to the different preferences of users that occur due to the difference in visiting frequency.

The present study can be summarized in the following three points.

1. In the present study, a system was designed and developed by integrating SNS, Web-GIS and recommendation system in order to recommend sightseeing spots to users with different visiting frequencies. This system reduced the burden of gathering sightseeing information to recommend sightseeing spots to users with different visiting frequencies and enabled the gathering and accumulation of sightseeing spot information. Kamakura City, Kanagawa Prefecture, Japan was selected as the operation target area, and the operation and evaluations of the system were conducted.

2. The operation of the system was conducted over the course of six weeks with people inside and outside the operation target area as subjects, and the total number of users was 61. A web questionnaire survey was conducted for users. Based on the results of this questionnaire survey, it revealed that recommendation system for sightseeing spots adopting two recommendation methods is effective in supporting the sightseeing activities of users with different visiting frequencies. 
3. The results of the access analysis made clear that the system was used in line with the purpose and design of the present study which was to enable the system to be used regardless of the type of device used, and support the sightseeing activities of users with different visiting frequencies adopting different methods. The total number of sessions in the system was 329. Regarding the devices used to access the system, $77 \%$ used mobile devices, and smartphones were used most frequently.

In regards to future research tasks, the improvement of the system according to the outcome in Section 6.3 as well as the improvement of its utilization significance by increasing performance records of the system in other urban sightseeing destinations can be raised.

Author Contributions: Yudai Kato design, develop and operate the sightseeing spot recommendation system that takes into account the visiting frequency of users in the present study. He also initially drafted the paper. Kayoko Yamamoto carried out background work, and evaluates the system. All authors contributed to write up and review, and approved the paper manuscript. All authors have read and agreed to the published version of the manuscript.

Funding: This research received no external funding.

Acknowledgments: In the operation of the sightseeing spot recommendation system and the web questionnaires survey of the present study, enormous cooperation was received from those mainly in the Kanto region such as Kanagawa Prefecture and Tokyo Metropolis. We would like to take this opportunity to gratefully acknowledge them.

Conflicts of Interest: The authors declare no conflict of interest.

\section{References}

1. Okamaura, K.; Fukushige, M. How to Promote Repeaters? Empirical Analysis of Tourist Survey Data in Kansai Region. KISER Disc. Pap. Ser. 2007, 10, 35.

2. Kamakura City. Issues on Sightseeing in Kamakura City. Available online: https://www.city.kamakura. kanagawa.jp/kankou/kankoujijouh28.html (accessed on 31 January 2020).

3. Anacleto, R.; Figueiredo, L.; Almeida, A.; Novais, P. Mobile Application to Provide Personalized Sightseeing Tours. J. Netw. Comput. Appl. 2014, 41, 56-64. [CrossRef]

4. Brilhante, I.R.; Macedo, J.A.; Nardini, F.M.; Perego, R.; Renso, C. On planning sightseeing tours with TripBuilder. Inf. Process. Manag. 2015, 51, 1-15. [CrossRef]

5. Zhou, J.; Yamamoto, K. Development of the System to Support Tourists' Excursion Behavior Using Augmented Reality. Int. J. Adv. Comput. Sci. Appl. 2016, 7, 197-209. [CrossRef]

6. Fujita, S.; Yamamoto, K. Development of Dynamic Real-Time Navigation System. Int. J. Adv. Comput. Sci. Appl. 2016, 7, 116-130. [CrossRef]

7. Makino, R.; Yamamoto, K. Spatiotemporal Information System Using Mixed Reality for Area-Based Learning and Sightseeing. In Computational Urban Planning and Management for Smart Cities; Geertman, S., Allan, A., Pettit, C., Stillwell, J., Eds.; Springer: Berlin, Germany, 2019; pp. 283-302.

8. Yamamoto, K. Navigation System for Foreign Tourists in Japan. J. Environ. Sci. Eng. 2018, 10, 521-541.

9. Abe, S.; Yoshitsugu, N.; Miki, D.; Yamamoto, K. An Information Retrieval System with Language-Barrier-Free Interfaces. J. Inf. Syst. Soc. Jpn. 2019, 14, 57-64.

10. Sasaki, R.; Yamamoto, K. A Sightseeing Support System Using Augmented Reality and Pictograms within Urban Tourist Areas in Japan. Int. J. Geo-Inf. 2019, 8, 381. [CrossRef]

11. McKercher, B.; Shoval, N.; Ng, E.; Birenboim, A. First and Repeat Visitor Behaviour: GPS Tracking and GIS Analysis in Hong Kong. Int. J. Tour. Space Place Environ. 2012, 14. [CrossRef]

12. Masuda, M.; Izumi, T.; Nakatani, Y. System that Promotes Repeat Tourists by Making Sightseeing Unfinished. Hum. Interface 2012, 14, 259-270. 
13. Yorozu, N.; Abe, A.; Ichikawa, H.; Tomizawa, H. Development of sightseeing Planning Support System That Take into Account Repeat Travellers. In Proceedings of the 77th Annual Meeting of the Information Processing Society of Japan, Kyoto, Japan, 30 April-1 May 2015; pp. 871-872.

14. Uchizono, Y.; Takayama, T. A Guide System That Induce Travellers' Revisit to Onomichi City. In Proceedings of the 78th Annual Meeting of the Information Processing Society of Japan, Yokohama, Japan, 11-14 April 2016; pp. 619-620.

15. Katayama, S.; Isogawa, N.; Obuchi, M.; Nishiyama, Y.; Okoshi, T.; Yonezawa, T.; Nakazawa, H.; Takashio, K.; Tokuda, H. SpoTrip: Evaluation of Information Provision System for Hidden Spots to Promote the Increase Repeat Travellers. IEICE Tech. Rep. 2017, 116, 185-192.

16. Niibara, S.; Takayama, T. A System That Provides the appropriate Levels of Information for Tourists. In Proceedings of the 79th Annual Meeting of the Information Processing Society of Japan, Nagoya, Japan, 16-18 March 2017; pp. 781-782.

17. Kang, S.; Lee, G.; Kim, J.; Park, D. Identifying the Spatial Structure of the Tourist Attraction System in South Korea Using GIS and Network Analysis: An Application of Anchor-Point Theory. J. Destin. Mark. Manag. 2018, 9, 358-370. [CrossRef]

18. Uchida, K.; Izumi, R.; Kunieda, T.; Yamada, S.; Yonetani, K.; Gotoda, A.; Yaegashi, M. Development "KadaSola": A Sightseeing Support System for Long Stay. In Proceedings of the 81st Annual Meeting of the Information Processing Society of Japan, Fukuoka, Japan, 14-16 March 2019; pp. 841-842.

19. Tarui, Y. Recommendation System of Tourist Site Using Collaborative Filtering Method and Contents Analysis Method. Bull. Dep. Manag. Inf. Sci. Jôbu Univ. 2011, 36, 1-14.

20. Yu, C.C.; Chang, H.P. Towards Context-Aware Recommendation for Personalized Mobile Travel Planning. In Context-Aware Systems and Applications; Cong, P., Nguyen, V., Nguyen, M.H., Tung, T., Suzuki, J., Eds.; Springer: Berlin, Germany, 2012; pp. 121-130.

21. Ikeda, T.; Yamamoto, K. Development of Social Recommendation GIS for Tourist Spots. Int. J. Adv. Comput. Sci. Appl. 2014, 5, 8-21. [CrossRef]

22. Mizutani, Y.; Yamamoto, K. A Sightseeing Spot Recommendation System That takes into Account the Change in Circumstances of Users. Int. J. Geo-Inf. 2017, 6, 303. [CrossRef]

23. Mukasa, Y.; Yamamoto, K. A Sightseeing Spot Recommendation System for Urban Smart Tourism Based on Users' Priority Conditions. J. Civ. Eng. Archit. 2019, 13, 622-640. [CrossRef]

24. Kitayama, D.; Ozu, K.; Nakajima, S.; Sumiya, K. A Route Recommender System Based on the User's Visit Duration at Sightseeing Locations. In Software Engineering Research, Management and Applications; Lee, R., Ed.; Springer: Berlin, Germany, 2014; pp. 177-190.

25. Gavalas, D.; Konstantopoulos, C.; Mastakas, K.; Pantziou, G. Mobile Recommender Systems in Tourism. J. Netw. Comput. Appl. 2014, 39, 319-333. [CrossRef]

26. Li, S.; Takahashi, S.; Yamada, K.; Takagi, M.; Sasaki, J. A Proposal of the Tourism Course Recommendation System (TCRS) for Foreign Tourists by Using Photo Data in Social Network Service. In New Trends in Intelligent Software Methodologies, Tools and Techniques; Fujita, H., Selamat, A., Omatu, S., Eds.; IOS Press: Amsterdam, The Netherlands, 2017; pp. 331-338.

27. Takahashi, S.; Li, S.; Yamada, K.; Takagi, M.; Sasaki, J. Case Study of Tourism Course Recommendation System Using Data from Social Network Services. In New Trends in Intelligent Software Methodologies, Tools and Techniques; Fujita, H., Selamat, A., Omatu, S., Eds.; IOS Press: Amsterdam, The Netherlands, 2017; pp. 339-347.

28. Aoike, T.; Ho, B.; Hara, T.; Ota, J.; Kurata, Y. Utilising Crowd Information of Tourist Spots in an Interactive Tour Recommender System. In Information and Communication Technologies in Tourism; Pesonen, J., Neidhardt, J., Eds.; Springer: Berlin, Germany, 2019; pp. 27-39.

29. Jannach, D.; Zanker, M.; Felfernig, A.; Friedrich, G. Recommender Systems: An Introduction; Cambridge University Press: Cambridge, UK, 2011.

30. Kamishima, T. Algorithms for recommender systems (2). Trans. Jpn. Soc. Artif. Intell. 2008, 23, 89-103.

31. Aggrawal, C.C. Recommender Systems: The Textbook; Springer: Berlin, Germany, 2016; p. 498.

32. 4travel.jp. Available online: https://4travel.jp/ (accessed on 31 January 2020). 
33. Jalan Kankou Guide. Available online: https://www.jalan.net/kankou/ (accessed on 31 January 2020).

34. Adachi, H.; Shioya, H. Study Report: Study on the Process of Forming Repeat Travellers; JTB Tourism Research \& Consulting Co.: Tokyo, Japan, 2007; p. 20.

(c)

(C) 2020 by the authors. Licensee MDPI, Basel, Switzerland. This article is an open access article distributed under the terms and conditions of the Creative Commons Attribution (CC BY) license (http://creativecommons.org/licenses/by/4.0/). 